\title{
Ponto de colheita e maturação de frutos de camu-camu colhidos em diferentes estádios
}

\author{
Patrícia Maria Pinto(1), Angelo Pedro Jacomino(1), Simone Rodrigues da Silva(1) \\ e Carolina Amanda Wippich Andrade ${ }^{(1)}$
}

(1)Universidade de São Paulo, Escola Superior de Agricultura Luiz de Queiroz, Departamento de Produção Vegetal, Avenida Pádua Dias,
no 11, Caixa Postal 09, CEP 13418-900 Piracicaba, SP. E-mail: patriciapmp@gmail.com, jacomino@usp.br, srsilva@usp.br, cwippich@gmail.com

Resumo - O objetivo deste trabalho foi determinar o ponto de colheita e caracterizar a pós-colheita de frutos de camu-camu (Myrciaria dubia) colhidos em diferentes estádios de maturação. A colheita dos frutos foi realizada em quatro estádios de maturação, definidos pela cor da casca: verde, verde-avermelhada, vermelho-esverdeada e roxa. O armazenamento foi feito em câmaras de refrigeração a $22 \pm 1{ }^{\circ} \mathrm{C}$ e $85 \pm 5 \%$ UR. Utilizou-se delineamento experimental inteiramente casualizado, em parcelas subdivididas no tempo, com cinco períodos de armazenamento: 0, 3, 6, 9 e 12 dias. Foram avaliados: atividade respiratória; produção de etileno; coloração da casca verificada pelo ângulo de cor e coordenadas de cromaticidade $a^{*}$ e $b^{*}$; firmeza; perda de massa de matéria fresca; teores de clorofilas, antocianinas, sólidos solúveis e ácido ascórbico; acidez titulável; e incidência de podridão. Os picos de produção de $\mathrm{CO}_{2}$ e etileno ocorreram após a colheita. Os teores de clorofilas e antocianinas variaram com a mudança na coloração da casca de verde para roxa, o que confirmou a maturação dos frutos. Os teores de ácido ascórbico variaram de $759,02 \mathrm{mg}$ por $100 \mathrm{~g}$, no estádio verde, a 1.071,12 mg por $100 \mathrm{~g}$, no roxo. Os frutos colhidos totalmente roxos têm reduzida vida pós-colheita. A maior qualidade pós-colheita do camu-camu é obtida quando os frutos são colhidos com coloração vermelho-esverdeada.

Termos para indexação: Myrciaria dubia, ácido ascórbico, amadurecimento, armazenamento, pós-colheita, qualidade.

\section{Harvest point and maturation of camu-camu fruit harvested at different stages}

\begin{abstract}
The objective of this work was to determine the harvest point and to characterize the postharvest of camu-camu (Myrciaria dubia) fruit harvested at different maturity stages. The fruits are harvested at four maturity stages, defined by skin color: green, reddish-green, red-greenish, and purple. Fruit were cold-stored at $22 \pm 1{ }^{\circ} \mathrm{C}$ and $85 \pm 5 \% \mathrm{RH}$. It was used a completely randomized design, split-potted in time, with five storage periods: $0,3,6,9$, and 12 days. Evaluations were made for: respiratory activity; ethylene production; skin color, determined with the hue angle and chromaticity coordinates $\mathrm{a}^{*}$ and $\mathrm{b}^{*}$; firmness; fresh matter weight loss; contents of chlorophyll, anthocyanins, soluble solids, and ascorbic acid; titratable acidity; and rot incidence. Peaks of $\mathrm{CO}_{2}$ and ethylene production occurred after harvest. The contents of chlorophyll and anthocyanins varied according to the changes in skin color, from green to purple, which confirmed fruit ripening. The contents of ascorbic acid ranged from $759.02 \mathrm{mg}$ per $100 \mathrm{~g}$, in the green stage, to $1,071.12 \mathrm{mg}$ per $100 \mathrm{~g}$, in the purple one. Fruit harvested with complete purpled skin had reduced postharvest life. Best postharvest quality for camu-camu is achieved when skin color is red-green.
\end{abstract}

Index terms: Myrciaria dubia, ascorbic acid, ripening, storage, postharvest, quality.

\section{Introdução}

O camu-camu [Myrciaria dubia (H.B.K.) Mcvaugh] é nativo da Amazônia, pertence à família Myrtaceae e é cultivado em pequena escala em vários estados brasileiros. Seu fruto é fonte de Vitamina C e possui teores de ácido ascórbico muito elevados, que variam de 960 a $6.000 \mathrm{mg}$ por $100 \mathrm{~g}$ de polpa (Donadio et al., 2002; Inoue et al., 2008; Albertino et al., 2009). Entre os frutos típicos da Amazônia, o camu-camu destaca-se também como fonte de antocianinas, com teores médios de $54 \mathrm{mg}$ por $100 \mathrm{~g}$ (Rodrigues \& Marx, 2006).

A casca do camu-camu é fina e apresenta coloração que varia de verde a roxa, quando o fruto está maduro (Zanatta \& Mercadante, 2007). Contudo, a elevada acidez da polpa restringe seu consumo, que ocorre principalmente na forma de sucos, néctares ou em pó (Maeda \& Andrade, 2003).

Níveis consideráveis de compostos nutracêuticos, como vitaminas, antocianinas, carotenoides e 
compostos fenólicos, além da alta capacidade antioxidante de frutos tropicais não tradicionais (Rufino et al., 2010) têm tornado promissoras as perspectivas para a exploração desses frutos. No entanto, dados sobre fisiologia e comportamento pós-colheita de frutos nativos da Região Amazônica são relativamente escassos. Apesar do potencial econômico destas espécies, pouco tem sido feito no sentido de torná-las aptas ao cultivo fora do local de origem. Além disso, estudos quanto à conservação e à comercialização desses frutos ainda são necessários.

O potencial de conservação e a qualidade dos frutos são determinados, principalmente, pelo estádio de maturação em que os frutos são colhidos. A colheita com os frutos em estádio adequado de maturação é importante para a boa conservação dos frutos, e afeta diretamente a manutenção de sua qualidade (Chitarra \& Chitarra, 2005). A atividade respiratória e a produção de etileno, bem como as mudanças físicas e químicas durante o desenvolvimento dos frutos, são critérios importantes para determinar a maturidade e a qualidade de frutos (Kluge, 2002). Assim, o estudo da fisiologia pós-colheita do camu-camu é de grande importância para determinar o momento ideal da colheita e caracterizar as alterações ocorridas nas características físicas, sensoriais e nutricionais dos frutos durante o armazenamento.

O objetivo deste trabalho foi determinar o ponto de colheita e caracterizar a pós-colheita de frutos de camu-camu colhidos em diferentes estádios de maturação.

\section{Material e Métodos}

Os frutos de camu-camu foram colhidos de plantas da Coleção de Frutas Tropicais, da Estação Experimental de Citricultura de Bebedouro, no Município de Bebedouro, SP $\left(20^{\circ} 56^{\prime} \mathrm{S}\right.$ e $\left.48^{\circ} 28^{\prime} \mathrm{W}\right)$, em quatro estádios de maturação definidos pela coloração da casca: 1 , verde; 2 , verde-avermelhada; 3, vermelho-esverdeada; e 4, roxa. Após a colheita, os frutos foram acondicionados em caixas de plástico forradas com espuma e transportados imediatamente para o Laboratório de Pós-Colheita de Produtos Hortícolas, do Departamento de Produção Vegetal, da Escola Superior de Agricultura Luiz de Queiroz, em Piracicaba, SP, a 247 km de distância de Bebedouro.

Os camu-camus foram armazenados em câmaras de refrigeração a $22 \pm 1^{\circ} \mathrm{C}$ e a $85 \pm 5 \%$ UR, até o completo amadurecimento ou senescência. Os frutos foram analisados diariamente quanto à atividade respiratória, produção de etileno, perda de massa de matéria fresca e incidência de podridão e, a cada três dias, quanto à firmeza da polpa, coloração da casca, teores de clorofila e antocianinas totais, teores de sólidos solúveis, acidez titulável e ácido ascórbico. Para a quantificação da atividade respiratória e produção de etileno, os camu-camus foram avaliados em sistema fechado, em que 10 frutos (100 g em média) foram acondicionados em frascos de vidro $(600 \mathrm{~mL})$ durante $60 \mathrm{~min}$. Após esse período, coletaram-se amostras gasosas de $1 \mathrm{~mL}$ do interior dos frascos, com seringa. As amostras foram injetadas em cromatógrafo a gás Trace 2000 GC (Thermo Finnigan, West Palm Beach, FL, EUA), e os resultados foram expressos em $\mathrm{mL} \mathrm{kg}^{-1}$ por hora de $\mathrm{CO}_{2}$ e de $\mathrm{C}_{2} \mathrm{H}_{4}$.

A perda de matéria fresca (\%) foi quantificada por meio da diferença entre a massa inicial e a massa final da amostra de 10 frutos, em balança semianalítica. A incidência de podridão (\%) foi avaliada visualmente, pela contagem do número de frutas com presença de lesões com diâmetro superior a $0,5 \mathrm{~cm}$. A firmeza da polpa $(\mathrm{N})$ foi avaliada com um penetrômetro digital, modelo Sammar 53200 (T.R. Turoni, Forli, Itália), pela perfuração da região equatorial dos frutos, com a leitura realizada em cada fruto.

A coloração da casca (ângulo de cor e coordenadas $a^{*}$ e $b^{*}$ ) foi determinada com colorímetro, modelo CR-300 (Minolta, Tóquio, Japão), tendo-se realizado duas leituras na região equatorial de cada fruto. Para as análises químicas, utilizou-se a polpa homogeneizada de 10 frutos. Os teores de sólidos solúveis ( ${ }^{\circ}$ Brix) foram determinados com refratômetro digital, modelo Palete 101 (Atago, Tóquio, Japão). A acidez titulável (percentagem de ácido cítrico) foi analisada por titulometria de neutralização com $\mathrm{NaOH}(1 \mathrm{~N})$, até $\mathrm{pH}$ 8,1 . O teor de ácido ascórbico (mg $100 \mathrm{~g}^{-1}$ ) também foi determinado por titulometria, com solução de 2,6-diclorofenol-indofenol (DCFI), de acordo com metodologia descrita por Carvalho et al. (1990).

Os teores de clorofila total $\left(\mathrm{mL} \mathrm{g}^{-1}\right)$ foram calculados por meio da metodologia descrita por Lichtenthaler (1987), e os de antocianina total (mg $100 \mathrm{~g}^{-1} \mathrm{de}$ polpa liofilizada) foram determinados de acordo com adaptação da metodologia descrita por Lee et al. (2005), tendo-se utilizado $0,5 \mathrm{~g}$ de polpa liofilizada de 
camu-camu, diluída em 4,5 mL de solução de $\mathrm{HCl}$ em metanol a $0,5 \%(\mathrm{v} / \mathrm{v})$.

Utilizou-se o delineamento estatístico inteiramente casualizado, com parcelas subdivididas no tempo (períodos de 0,3, 6, 9 e 12 dias de armazenamento), com cinco repetições compostas de 10 frutos. Utilizou-se o programa Sisvar para a análise estatística dos resultados.

\section{Resultados e Discussão}

Os camu-camus colhidos nos estádios de maturação 1,2 e 3 apresentaram produção de $\mathrm{CO}_{2}$ entre 8 e $10 \mathrm{~mL} \mathrm{~kg}^{-1} \mathrm{~h}^{-1}$, enquanto os colhidos no estádio 4 produziram aproximadamente $17 \mathrm{~mL} \mathrm{~kg}^{-1} \mathrm{~h}^{-1}$. Com o avanço dos dias de armazenamento, a atividade respiratória aumentou nos frutos de todos os estádios e alcançou máxima produção entre o $3^{\underline{0}}$ e o $6^{0}$ dia (Figura 1). Após este período, a produção de $\mathrm{CO}_{2}$ diminuiu em todos os frutos, tendo atingido valores inferiores aos obtidos na colheita.

Quanto ao etileno, independentemente do estádio de maturação, os frutos apresentaram aumento na produção após a colheita (Figura 1). Nos camu-camus colhidos no estádio 1, esse aumento foi superior à produção de etileno dos frutos colhidos nos demais estádios de maturação. Nesse estádio, a elevação ocorreu após o 3 o dia, e o pico ocorreu entre o 7o e $8^{\circ}$ dia após a colheita, com produção de mais de $5 \mu \mathrm{L} \mathrm{kg}^{-1} \mathrm{~h}^{-1}$. Os frutos do estádio 2 apresentaram elevação na produção de etileno após o $2^{\circ}$ dia de armazenamento, com pico de produção no 7으 dia após a colheita. Os frutos dos estádios 3 e 4 apresentaram elevação no $4^{\circ}$ dia após a colheita. A maior demora na elevação na produção de etileno nos estádios mais avançados de maturação ocorreu porque os camu-camus colhidos maduros provavelmente já estavam em uma fase adiantada da produção de etileno. De acordo com Lelièvre et al. (1997), certos frutos colhidos verdes necessitam produzir o hormônio para desencadear o amadurecimento e senescência. Dessa forma, a produção de etileno é fundamental para o amadurecimento desses frutos, pois age como regulador de vias metabólicas dependentes do hormônio.

Com base na atividade respiratória e na produção de etileno, pode-se inferir que os camu-camus apresentam comportamento típico de frutos climatéricos, caracterizados pela produção autocatalítica de etileno antes, durante ou depois do aumento na produção de $\mathrm{CO}_{2}$, que têm seus processos de amadurecimento continuados após a colheita do fruto fisiologicamente maduro. Carrillo et al. (2011) também verificaram este comportamento em camu-camus colhidos semimaduros e maduros. No entanto, alguns autores classificaram o camu-camu como fruto não climatérico (Andrade et al., 1991; Pinedo, 2002). Estes autores relataram que esse fruto, quando colhido verde, não consegue alcançar sua maturidade total. Esses autores provavelmente colheram o camu-camu antes de sua maturidade fisiológica. No presente trabalho, mostrou-se que, além de os frutos apresentarem aumento da atividade respiratória e da produção de etileno, eles evoluíram

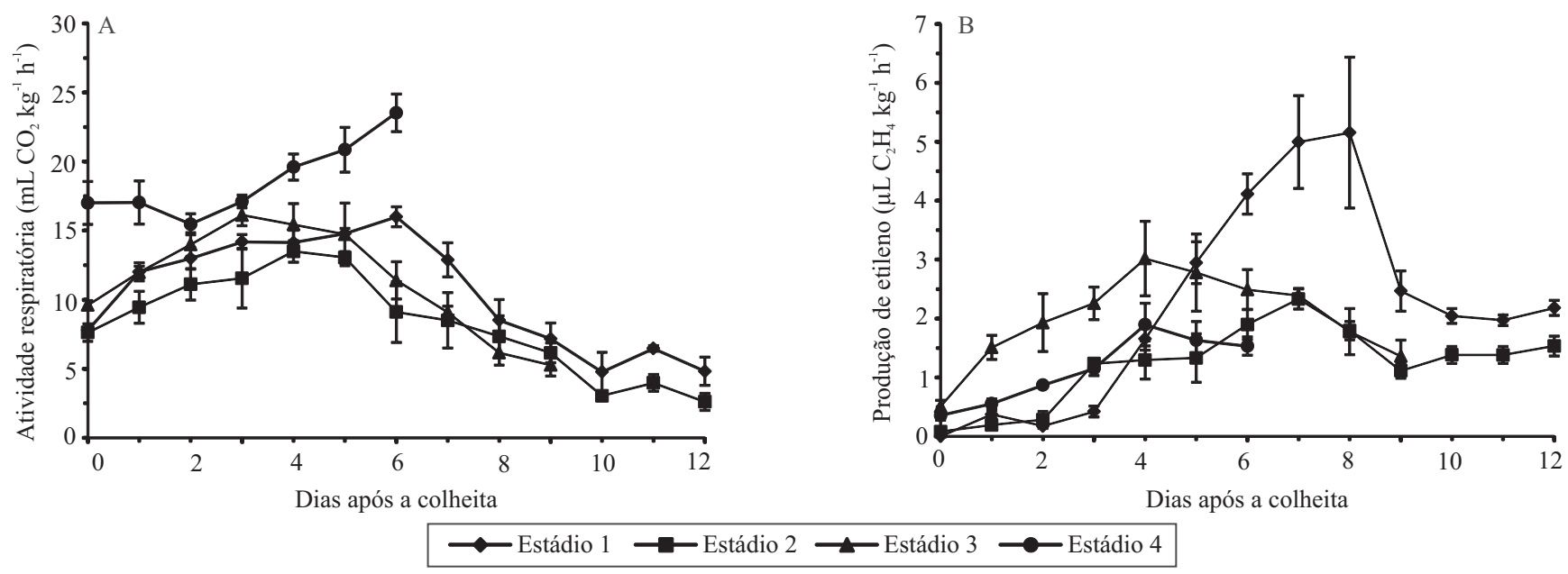

Figura 1. Atividade respiratória (A) e produção de etileno (B), em frutos de camu-camu colhidos em quatro estádios de maturação - 1, verde; 2 , verde-avermelhado; 3, vermelho-esverdeado; e 4, roxo -, armazenados a $22 \pm 1{ }^{\circ} \mathrm{C}$ e $85 \pm 5 \%$ UR, durante 12 dias. 
na qualidade, tanto em atributos físicos quanto em químicos. O grande aumento da produção de etileno, no início do amadurecimento dos frutos climatéricos, é considerado como um dos principais fatores iniciadores das modificações de cor, aroma e textura, bem como de outros atributos bioquímicos e fisiológicos (Chitarra \& Chitarra, 2005).

A perda de massa é um dos principais fatores envolvidos na pós-colheita de produtos hortícolas. Os camu-camus colhidos nos estádios 2, 3 e 4 apresentaram perdas de massa semelhantes, durante o armazenamento (Figura 2). Os frutos colhidos no estádio 1 (verde) foram os que apresentaram a maior perda de massa, tendo atingido valores próximos a $15 \%$ no $12^{\circ}$ dia. A perda de massa pode ser atribuída à perda de umidade e de material de reserva respectivamente pela transpiração e respiração, fatores limitantes à vida útil dos frutos (Chitarra \& Chitarra, 2005). Resultados similares foram encontrados por Andrade et al. (2010), em camu-camus colhidos em diferentes estádios de maturação. Os autores verificaram que a perda de massa foi maior nos frutos mais verdes do que nos frutos mais maduros.

O camu-camu mostrou-se bastante perecível, quando colhido nos estádios mais avançados de maturação. Os frutos colhidos nos estádios 1 e 2 conservaram-se

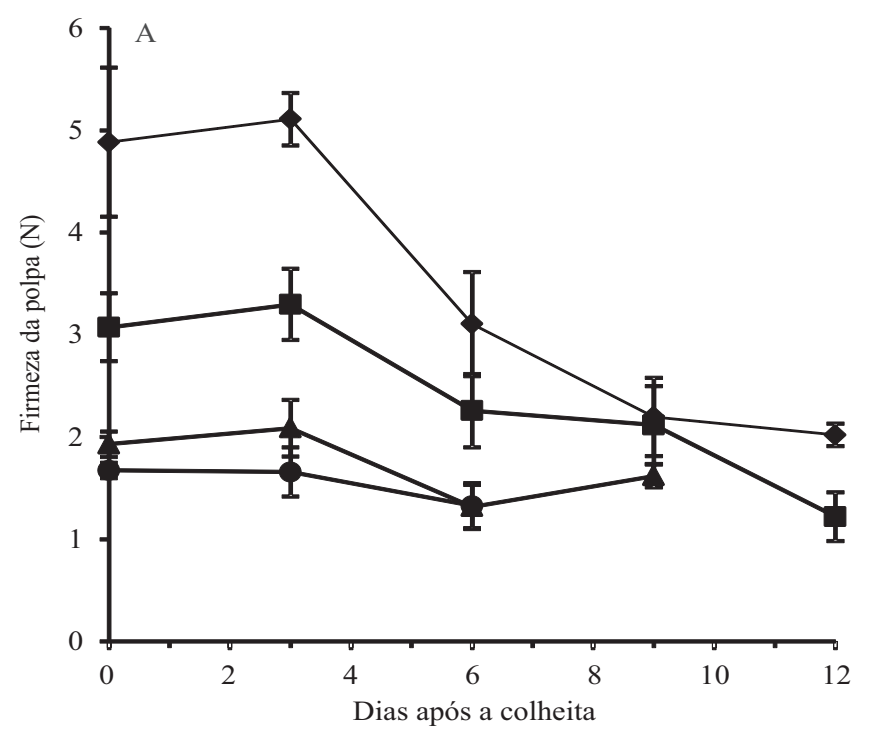

até o $12^{\circ}$ dia, enquanto os colhidos nos estádios 3 e 4 tiveram vida pós-colheita de 9 e 6 dias, respectivamente (Figura 3). A partir do $3^{\mathrm{o}}$ dia de armazenamento, sintomas de podridão foram constatados nos frutos do estádio 4 e, no $7^{\circ}$ dia, $100 \%$ dos frutos desse estádio estavam comprometidos. Os frutos colhidos no estádio 3 apresentaramlesõesapartirdo $4^{\circ}$ dia, quecomprometeram $100 \%$ dos frutos no $10^{\circ}$ dia; enquanto frutos colhidos nos estádios 1 e 2 apresentaram lesões somente no $10^{\circ} \mathrm{e}$ no $6^{\circ}$ dia, respectivamente, que atingiram 38 e $63 \%$ dos frutos, ao final do armazenamento.

Em relação à firmeza, os frutos colhidos no estádio 1 apresentaram os maiores valores, no momento da colheita, seguidos pelos dos estádios 2, 3 e 4; porém, os dois últimos não diferiram entre si (Figura 2). No decorrer do armazenamento, os frutos colhidos nos estádios 1, 2 e 3 apresentaram comportamento semelhante quanto à perda de firmeza, com redução significativa dos valores, principalmente após o $3^{\text {o }}$ dia, nos frutos dos estádios 1 e 2 , e o $6^{-}$dia, nos do estádio 3. Os frutos sofreram rápida perda de firmeza da polpa, independentemente do estádio de maturação, ressalva feita apenas aos camu-camus colhidos no estádio 4, os quais mostraram firmeza baixa e estável ao longo do armazenamento. O amolecimento da polpa pode ser atribuído à atividade de enzimas hidrolíticas,

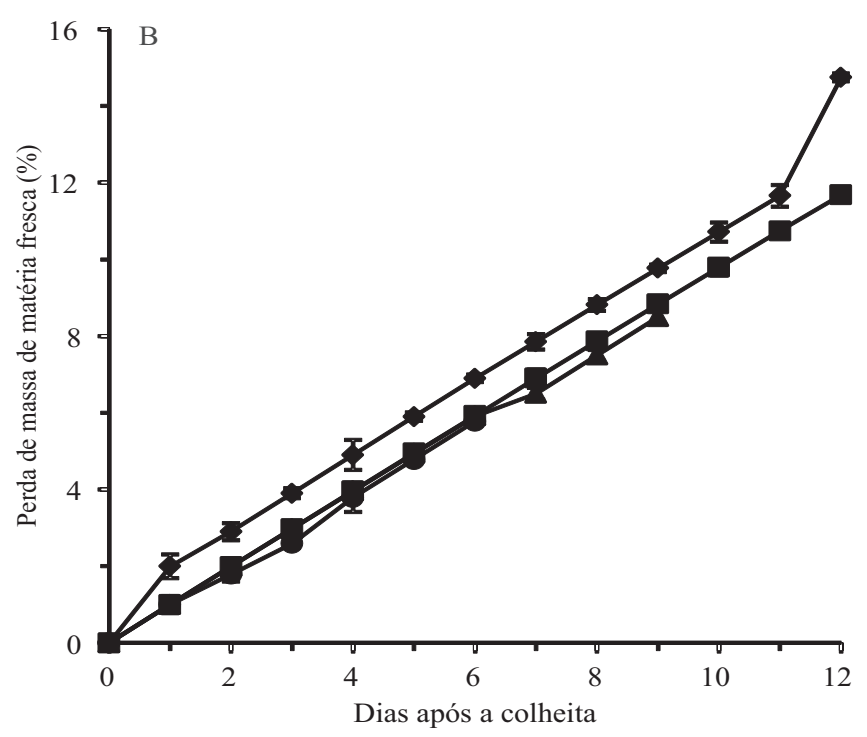

๑Estádio $1 \longrightarrow$ Estádio $2 \multimap$ Estádio $3 \multimap$ Estádio 4

Figura 2. Firmeza da polpa (A) e perda de massa de matéria fresca (B), em frutos de camu-camu colhidos em quatro estádios de maturação - 1, verde; 2, verde-avermelhado; 3, vermelho-esverdeado; e 4, roxo -, armazenados a $22 \pm 1^{\circ} \mathrm{C}$ e $85 \pm 5 \%$ UR, durante 12 dias. 
como a poligalacturonase e pectinametilesterase, que promovem intensa solubilização das pectinas, constituintes da parede celular, o que resulta em perda de firmeza (Anthon et al., 2002; Silva et al., 2009).

O ângulo de cor e as coordenadas de cromaticidade $a^{*}$ e b* expressaram com exatidão as diferenças na coloração da casca dos camu-camus e permitiram uma visualização precisa da mudança de cor após a colheita (Tabela 1). O ângulo de cor, no momento da colheita, foi de: $111,40^{\circ}$, nos frutos colhidos no estádio 1 (verde); 80,21 ${ }^{\circ}$, nos frutos colhidos no estádio 2 (verde-avermelhado); $2,43^{\circ}$, nos frutos do estádio 3 (vermelho-esverdeado); e $334,46^{\circ}$, nos frutos do estádio 4 (roxo). As variações do ângulo de cor ao longo do armazenamento confirmaram o avanço do amadurecimento dos frutos. Frutos colhidos no estádio 4 mantiveram sua coloração sem diferença significativa entre os períodos de armazenamento. Os valores de $a^{*}$ e $b^{*}$ foram significativamente diferentes nos frutos colhidos em cada estádio de maturação. Os camu-camus colhidos em estádios menos avançados de maturação apresentaram valores negativos para a coordenada $\mathrm{a}^{*}$, correspondente à cor verde. No entanto, os frutos colhidos nos estádios mais maduros apresentaram valores positivos para a mesma coordenada, o que identifica a cor vermelha. Observouse, também, que os frutos colhidos no estádio 4 apresentaram valores negativos em b* (cor azul), o que comprova a tonalidade roxa dos camu-camus quando totalmente maduros. Durante a pós-colheita, a coloração da casca dos frutos do estádio 1 passou de verde para vermelho-esverdeada, em que os valores

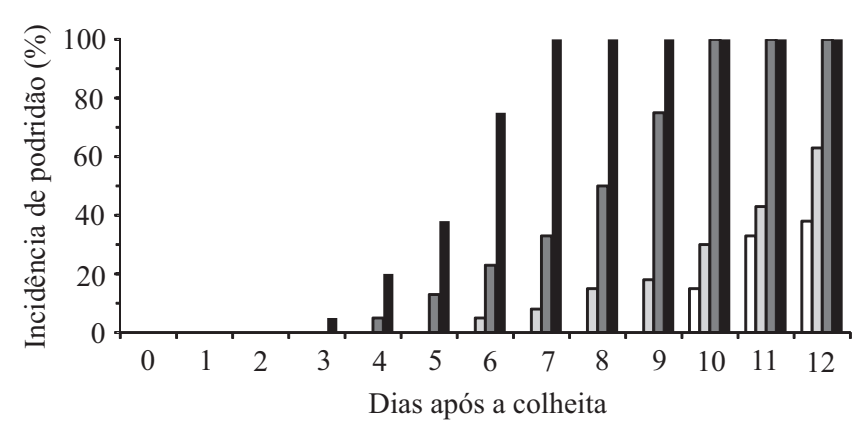

$$
\begin{array}{|llll|}
\hline \text { Estádio } 1 & \square \text { Estádio } 2 & \text { 口Estádio } 3 & \text { Estádio } 4 \\
\hline
\end{array}
$$

Figura 3. Incidência de podridão em frutos de camu-camu colhidos em quatro estádios de maturação - 1, verde; 2 , verde-avermelhado; 3, vermelho-esverdeado; e 4, roxo -, armazenados a $22 \pm 1^{\circ} \mathrm{C}$ e $85 \pm 5 \%$ UR, durante 12 dias. de a* tornaram-se positivos. Os frutos dos estádios 2, 3 e 4 apresentaram valores de $a^{*}$ e $b^{*}$ correspondentes à coloração roxa, ao final do armazenamento. Carrillo et al. (2011) também observaram modificação na cor da casca durante a pós-colheita de camu-camus produzidos no Estado do Amazonas, local de origem do fruto.

As mudanças da coloração da casca foram condizentes com os resultados obtidos nas análises de pigmentos, clorofilas e antocianinas (Figura 4). No momento da colheita, os maiores teores de clorofilas totais foram encontrados nos camu-camus do estádio 1, seguido dos estádios 2, 3 e 4. Após a colheita, houve degradação da clorofila e redução dos teores desse pigmento nos frutos. Ao final do armazenamento, os frutos dos estádios 2 e 3 apresentaram níveis semelhantes aos encontrados nos camu-camus colhidos totalmente maduros. Concomitantemente, a análise de antocianinas totais apresentou resultado contrário ao da clorofila. Na colheita, os frutos com os maiores teores de antocianinas foram os colhidos no estádio 4. Com o tempo de armazenamento, estes níveis aumentaram significativamente nos demais estádios, o que confirma a correspondência entre a síntese de antocianinas e a mudança na coloração dos camu-camus. Andrade et al. (2010) avaliaram o teor de antocianinas totais em camu-camus colhidos em cinco estádios de maturação,

Tabela 1. Coloração da casca de frutos de camu-camu colhidos em quatro estádios de maturação e armazenados a $22 \pm 1^{\circ} \mathrm{C}$ e $85 \pm 5 \%$ UR, durante 12 dias $^{(1)}$.

\begin{tabular}{lccccc}
\hline Estádio $^{(2)}$ & \multicolumn{5}{c}{ Dias de armazenamento } \\
\cline { 2 - 6 } & 0 & \multicolumn{5}{c}{6} & 9 & 12 \\
\hline \multirow{5}{c}{ Angulo de cor $\left(\mathrm{h}^{\circ}\right)$} \\
2 & $111,40 \mathrm{Ba}$ & $110,72 \mathrm{Ca}$ & $77,15 \mathrm{Cb}$ & $4,23 \mathrm{Cc}$ & $357,21 \mathrm{Ad}$ \\
3 & $80,21 \mathrm{Ca}$ & $31,25 \mathrm{Db}$ & $5,43 \mathrm{Dc}$ & $345,78 \mathrm{Ad}$ & $331,82 \mathrm{Be}$ \\
4 & $2,43 \mathrm{Da}$ & $358,24 \mathrm{Ab}$ & $345,12 \mathrm{Ac}$ & $333,37 \mathrm{Bd}$ & - \\
\hline \multicolumn{5}{c}{ Cromaticidade a* } \\
1 & $334,46 \mathrm{Aa}$ & $336,6 \mathrm{Ba}$ & $331,54 \mathrm{Ba}$ & - & - \\
2 & $-12,06 \mathrm{Da}$ & $-2,58 \mathrm{Cb}$ & $6,26 \mathrm{Bc}$ & $5,18 \mathrm{Bc}$ & $12,54 \mathrm{Ad}$ \\
3 & $-1,64 \mathrm{Ca}$ & $3,42 \mathrm{BCb}$ & $11,39 \mathrm{Ac}$ & $12,62 \mathrm{Ac}$ & $5,79 \mathrm{Bb}$ \\
4 & $11,54 \mathrm{Aa}$ & $11,42 \mathrm{Aa}$ & $11,08 \mathrm{Aa}$ & $5,82 \mathrm{Bb}$ & - \\
\hline \multicolumn{5}{c}{$\mathrm{Cromaticidade} \mathrm{b}^{*}$} \\
1 & $6,68 \mathrm{Ba}$ & $6,62 \mathrm{Ba}$ & $5,26 \mathrm{Ba}$ & - & - \\
2 & $30,90 \mathrm{Aa}$ & $30,87 \mathrm{Aa}$ & $25,69 \mathrm{Aa}$ & $16,05 \mathrm{Ab}$ & $13,63 \mathrm{Ab}$ \\
3 & $23,89 \mathrm{Ba}$ & $18,62 \mathrm{Ba}$ & $9,58 \mathrm{Bb}$ & $4,73 \mathrm{Bc}$ & $2,03 \mathrm{Bd}$ \\
4 & $4,98 \mathrm{Ca}$ & $2,32 \mathrm{BCa}$ & $1,82 \mathrm{Cb}$ & $1,33 \mathrm{Cb}$ & - \\
\hline
\end{tabular}

(1)Médias seguidas por letras iguais, maiúsculas nas colunas e minúsculas nas linhas, não diferem pelo teste de Tukey, a 5\% de probabilidade.

${ }^{(2)}$ Estádio 1, verde; 2, verde-avermelhado; 3, vermelho-esverdeado; e 4, roxo. 
e também observaram que frutos mais maduros apresentaram valores mais elevados deste pigmento. No entanto, os valores encontrados por esses autores foram inferiores aos obtidos no presente trabalho, o que pode ser decorrência do local onde os frutos foram produzidos.

Os teores de sólidos solúveis não diferiram significativamente entre os frutos colhidos nos estádios 1 e 2, no momento da colheita e durante o armazenamento
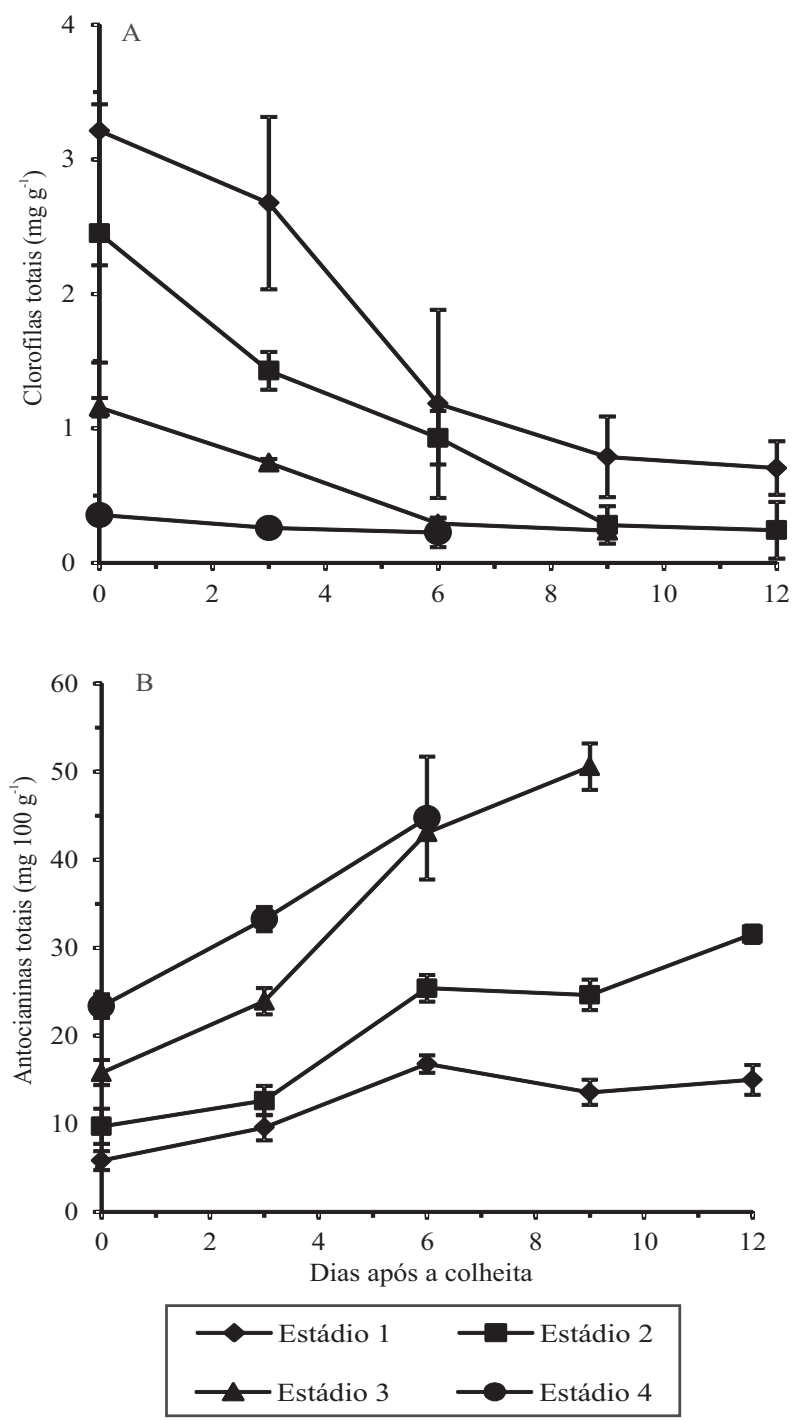

Figura 4. Teores de clorofilas totais (A) e antocianinas totais (B), em frutos de camu-camu colhidos em quatro estádios de maturação - 1, verde; 2 , verde-avermelhado; 3 , vermelhoesverdeado; e 4 , roxo -, armazenados a $22 \pm 1{ }^{\circ} \mathrm{C}$ e $85 \pm 5 \%$ UR, durante 12 dias.
(Tabela 2). Nos frutos colhidos nos estádios 3 e 4, os teores de sólidos solúveis foram significativamente superiores aos dos demais tratamentos. No estádio 3, os frutos foram colhidos com $7,54^{\circ}$ Brix; no estádio 4, com $8,45^{\circ}$ Brix. Esses teores mantiveram-se estáveis por todo o período de armazenamento. Silva \& Andrade (1997) e Andrade et al. (2010) relataram teores de sólidos solúveis máximos por ocasião do fim da maturação, em camu-camus colhidos em diferentes estádios.

A acidez titulável no momento da colheita foi maior nos frutos colhidos no estádio 1 , com $2,87 \%$ de ácido cítrico (Tabela 2). Nos demais estádios, os teores de ácido cítrico foram de: 2,77\%, para os frutos do estádio $2 ; 2,64 \%$, para os do estádio 3; e 2,65\%, para os colhidos no estádio 4. Observou-se, no decorrer do armazenamento, que os valores de acidez diminuíram em todos os estádios, o que era esperado com o amadurecimento dos frutos. Esses resultados estão de acordo com os encontrados por Silva \& Andrade (1997) e Andrade et al. (2010).

O teor de ácido ascórbico nos frutos colhidos no estádio 4 foi significativamente maior no momento da colheita e assim se manteve durante o período de armazenamento (Tabela 2). A variação do teor de ácido ascórbico, no momento da colheita, foi de $759,02 \mathrm{mg}$ $100 \mathrm{~g}^{-1}$ de polpa, nos frutos do estádio 1 , a $1.071,12 \mathrm{mg}$

Tabela 2. Composição química de frutos de camu-camu colhidos em quatro estádios de maturação e armazenados a $22 \pm 1^{\circ} \mathrm{C}$ e $85 \pm 5 \%$ UR, durante 12 dias $^{(1)}$.

\begin{tabular}{lccccc}
\hline Estádio $^{(2)}$ & \multicolumn{5}{c}{ Dias de armazenamento } \\
\cline { 2 - 6 } & 0 & \multicolumn{5}{c}{3} & 6 & 9 \\
\hline \multirow{5}{c}{ Sólidos solúveis ( $\left.{ }^{\circ} \mathrm{Brix}\right)$} \\
2 & $6,09 \mathrm{Cb}$ & $6,16 \mathrm{Cab}$ & $5,98 \mathrm{Cb}$ & $6,44 \mathrm{Ba}$ & $6,26 \mathrm{Aa}$ \\
3 & $6,14 \mathrm{Cab}$ & $5,98 \mathrm{Cb}$ & $5,80 \mathrm{Cb}$ & $6,59 \mathrm{Ba}$ & $6,09 \mathrm{Aab}$ \\
4 & $7,54 \mathrm{Ba}$ & $7,40 \mathrm{Ba}$ & $7,34 \mathrm{Ba}$ & $7,33 \mathrm{Aa}$ & - \\
\hline \multicolumn{5}{c}{ Acidez titulável (\% ácido cítrico) } \\
1 & $8,45 \mathrm{Aa}$ & $8,25 \mathrm{Aa}$ & $8,05 \mathrm{Aa}$ & - & - \\
2 & $2,87 \mathrm{Aa}$ & $2,67 \mathrm{Aab}$ & $2,52 \mathrm{Abc}$ & $2,47 \mathrm{Abc}$ & $2,36 \mathrm{Bc}$ \\
3 & $2,77 \mathrm{Ba}$ & $2,63 \mathrm{Aab}$ & $2,50 \mathrm{Ab}$ & $2,53 \mathrm{Ab}$ & $2,51 \mathrm{Ab}$ \\
4 & $2,64 \mathrm{Ba}$ & $2,57 \mathrm{Ab}$ & $2,51 \mathrm{Ab}$ & $2,50 \mathrm{Ab}$ & - \\
\hline \multicolumn{5}{c}{ Ácido ascórbico (mg $\left.100 \mathrm{~g}^{-1}\right)$} \\
1 & $2,65 \mathrm{Ba}$ & $2,52 \mathrm{Ab}$ & $2,41 \mathrm{Ac}$ & - \\
2 & $759,02 \mathrm{Dd}$ & $1129,71 \mathrm{Dc}$ & $1207,18 \mathrm{Da}$ & $1130,79 \mathrm{Bc}$ & $1172,08 \mathrm{Bb}$ \\
3 & $836,43 \mathrm{Cd}$ & $1178,52 \mathrm{Cc}$ & $1240,33 \mathrm{Cb}$ & $1275,01 \mathrm{Aa}$ & $1288,95 \mathrm{Aa}$ \\
4 & $914,79 \mathrm{Bc}$ & $1304,76 \mathrm{Ba}$ & $1284,16 \mathrm{Bb}$ & $1286,98 \mathrm{Ab}$ & - \\
\hline
\end{tabular}

${ }^{(1)}$ Médias seguidas por letras iguais, maiúsculas nas colunas e minúsculas nas linhas, não diferem pelo teste de Tukey, a 5\% de probabilidade. (2) Estádio 1, verde; 2, verde-avermelhado; 3, vermelho-esverdeado; e 4, roxo. 
$100 \mathrm{~g}^{-1}$ de polpa, nos frutos colhidos no estádio 4. Durante o armazenamento, ocorreu aumento significativo do teor de ácido ascórbico em todos os estádios de maturação, sendo maior nos frutos mais maduros, o que é favorável para sua comercialização. Zapata et al. (1993) também observaram que os conteúdos de ácido ascórbico foram maiores nos frutos colhidos em estádios de maturação mais avançados. $\mathrm{O}$ aumento do teor de ácido ascórbico em frutos, durante o amadurecimento, está associado ao aumento da síntese de intermediários metabólicos, os quais são precursores do ácido ascórbico. A degradação de polissacarídeos da parede celular, possivelmente, resulta em aumento de galactose, que é um dos precursores da biossíntese do ácido ascórbico (Smirnoff et al., 2001).

As transformações fisiológicas, físicas e químicas após a colheita foram constatadas pelo aumento da atividade respiratória, associada ao aumento da produção de etileno, mudança de coloração da casca dos frutos, perda de firmeza e de massa, redução da acidez titulável e aumento dos teores de ácido ascórbico. Essas diferenças observadas entre a colheita e o período de armazenamento dos frutos mostraram que o camu-camu é um fruto de comportamento climatérico e, por esse motivo, a colheita pode ocorrer em estádio de maturação menos avançado, o que possibilita uma vida pós-colheita maior. No entanto, os camu-camus colhidos nos estádios 1 e 2 não alcançaram os resultados verificados em alguns dos atributos de qualidade, referentes aos frutos colhidos mais maduros.

\section{Conclusões}

1. O estádio de maturação com a coloração de casca vermelho-esverdeada é o mais apropriado para a colheita do camu-camu.

2. Camu-camus colhidos nos estádios mais verdes têm maior vida pós-colheita; no entanto, os frutos colhidos nos estádios mais maduros apresentam qualidade superior.

3. Os frutos colhidos totalmente roxos têm reduzida vida pós-colheita.

\section{Agradecimentos}

À Estação Experimental de Citricultura de Bebedouro, pelo fornecimento dos frutos de camu-camu e à Fundação de Amparo à Pesquisa do Estado de São Paulo (Fapesp), pelo apoio financeiro.

\section{Referências}

ALBERTINO, A.; BARGE, A.; CRAVOTTO, G.; GENZINI, L.; GOBETTO, R.; VINCENTI, M. Natural origin of ascorbic acid: validation by 13C NMR and IRMS. Food Chemistry, v.112, p.715-720, 2009. DOI: 10.1016/j.foodchem.2008.05.114.

ANDRADE, J.S.; GALEZZI, M.A.; ARAGÃO, C.G.; CHAVES-FLORES, W.B. Valor nutricional do camu-camu (Myciaria dubia) cultivado em terra firme na Amazônia central. Revista Brasileira de Fruticultura, v.13, p.307-311, 1991.

ANDRADE, J.S.; SILVEIRA, J.S.; FERREIRA, S.A.N.; BRASIL, J.E.B. Effects of ripening stage and environment conditions on stored postharvest camu-camu (Myrciaria dubia McVaugh) fruits. Acta Horticulturae, n.864, p.423-429, 2010.

ANTHON, G.E.; SEKINE, Y.; WATANABE, N. Thermal inactivation of pectin methylesterase, polygalacturonase, and peroxidase in tomato juice. Journal of Agricultural and Food Chemistry, v.50, p.6153- 6159, 2002. DOI: 10.1021/jf020462r.

CARRILlO, M.P.; HERNÁNDEZ, M.S.; CARDONA, J.E.C.; BARRERA, J.; MARTÍNEZ, O.; FERNÁNDEZ-TRUJILLO, J.P. Prolonging postharvest quality of camu-camu (Myrciaria dubia H.B.K.) as the first step in the commercial chain. Acta Horticulturae, v.906, p.31-36, 2011.

CARVALHO, C.R.L.; MANTOVANI, D.M.B.; CARVALHO, P.R.N.; MORAES, R.M.M. Análises químicas de alimentos. Campinas: ITAL, 1990. 121p.

CHITARRA, M.I.F.; CHITARRA, A.B. Pós-colheita de frutos e hortaliças: fisiologia e manuseio. 2.ed. Lavras: UFLA, 2005. 785p.

DONADIO, L.C.; MORO, F.V.; SERVIDONE, A.A. Frutas brasileiras. Jaboticabal: Funep, 2002. 288p.

INOUE, T.; KOMODA, H.; UCHIDA, T.; NODE, K. Tropical fruit camu-camu (Myrciaria dubia) has anti-oxidative and anti-inflammatory properties. Journal of Cardiology, v.52, p.127-132, 2008. DOI: 10.1016/j.jjcc.2008.06.004.

KLUGE, R.A.; NACHTIGAL, J.C.; FACHINELLO, J.C.; BILHALVA, A.B. Fisiologia e manejo pós-colheita de frutas de clima temperado. 2.ed. Campinas: Rural, 2002. 214p.

LEE, L.J.; DURST, R.W.; WROLSTAD, R.E. Determination of total monomeric anthocyanin pigment content of fruit juices, beverages, natural colorants, and wines by the $\mathrm{pH}$ differential method: collaborative study. Journal of AOAC International, v.88, p.1269-1278, 2005.

LELIÈVRE, J.-M.; LATCHÈ, A.; JONES, B.; BOUZAYEN, M.; PECH, J.-C. Ethylene and fruit ripening. Physiologia Plantarum, v.101, p.727-739, 1997. DOI: 10.1111/j.1399-3054.1997. tb01057.x.

LICHTENTHALER, H.K. Chlorophylls and carotenoids: pigments of photosynthetic biomembranes. Methods of Enzymology, v.148, p.350-382, 1987. DOI: 10.1016/0076-6879(87)48036-1.

MAEDA, R.N.; ANDRADE, J.S. Aproveitamento do camu-camu (Myrciaria dubia) para produção de bebida alcoólica fermentada. Acta Amazonica, v.33, p.489-498, 2003. DOI: 10.1590/ S0044-59672003000300014. 
PINEDO, A.R. Manutenção dos atributos de qualidade do camu-camu desidratado durante o armazenamento. 2002. 96p. Dissertação (Mestrado) - Universidade Estadual de Campinas, Campinas.

RODRIGUES, R.B.; MARX, F. Camu-camu [Myrciaria dubia (H.B.K.) Mc Vaugh]: a promising fruit from the Amazon Basin. Nutrition, v.30, p.376-381, 2006.

RUFINO, M. do S.M.; ALVES, R.E.; BRITO, E.S. de; PÉREZ-JIMÉNEZ, J.; SAURA-CALIXTO, F.; MANCINI-FILHO, J. Bioactive compounds and antioxidant capacities of 18 non-traditional tropical fruits from Brazil. Food Chemistry, v.121, p.996-1002, 2010. DOI: 10.1016/j.foodchem.2010.01.037.

SILVA, C.T.C.; ANDRADE, J.S. Postharvest modifications in camu-camu fruit (Myrciaria dubia McVaugh) in response to stage of maturation and modified atmosphere. Acta Horticulturae, v.452, p.23-26, 1997.
SILVA, P.A.; ABREU, C.M.P. de; CORREA, A.D.; ASMAR, S.A. Modificações nas atividades da poligalacturonase e pectinametilesterase em morangos armazenados à temperatura ambiente. Ciência e Agrotecnologia, v.33, p.1953-1958, 2009. DOI: $10.1590 / \mathrm{S} 1413-70542009000700044$.

SMIRNOFF, N.; CONKLIN, P.; LOEWUS, F.A. Biosynthesis of ascorbic acid in plants: a renaissance. Annual Review of Plant Physiology and Plant Molecular Biology, v.52, p.437-467, 2001. DOI: 10.1146/annurev.arplant.52.1.437.

ZANATTA, C.F.; MERCADANTE, A.Z. Carotenoid composition from the Brazilian tropical fruit camu-camu (Myrciaria dubia). Food Chemistry, v.101, p.1526-1532, 2007. DOI: 10.1016/j. foodchem.2006.04.004.

ZAPATA, S.M.; DUFOUR, J.P. Camu-camu Myrciaria dubia (H.B.K.) McVaugh: chemical composition of fruit. Journal of the Science of Food and Agriculture, v.61, p.349-351, 1993. DOI: $10.1002 /$ jsfa. 2740610310 .

Recebido em 12 de julho de 2012 e aprovado em 24 de maio de 2013 